these even to attend classes if they are held at any distance from the home.

The remarks of your correspondent on local government cannot be too strongly emphasised and it is earnestly to be hoped that the present Government will give attention to this most important social question. The Local Government Board should have fuller powers for dealing with rural councils who neglect their duty and medical officers of health and inspectors of nuisances should not be subservient to individuals many of whom arm themselves with authority in order to block reform and guard slum interests. In one respect only my experience has differed from that of a Suffolk medical officer. I have been unfortunate enough to find quite as much insanitation, dilapidation, neglect, and overcrowding on properties belonging to large owners and to corporate and charitable bodies as on those belonging to small men.

I am, Sirs, yours faithfully,

C. Cochrane,

St. Neots, Feu. 10th, 1906

$$
\begin{aligned}
& \text { Member of the Royal Sanitary } \\
& \text { Institute. }
\end{aligned}
$$

To the Editors of THE LANCET.

SIRs, - There is no doubt that the question of providing better cottages for labourers is one of pressing importance in many rural districts. The relation, however, between a high rate of illegitimacy and districts in which the cottage accommodation leaves much to be desired is not quite so striking as it appears from the communication of a "Suffolk Poor-law Medical Officer" in THE LANCET of Feb. 10th, p. 404. The amount of illegitimacy can only be accurately estimated if it is given as a proportion of births to the number of unmarried and widowed women at child-bearing ages. Estimated in this way there were in 1901 (and I take this year as being the census year and therefore one in which we have information as to the number of women at the age given) 6.4 illegitimate births per 1000 unmarried and widowed womem between the ages of 15 and 45 years in Somerset, 8.6 in Wiltshire, and 10.8 in Herefordshire, three agricultural counties. In Durham county the proportion per 1000 was $11 \cdot 8$, in Stafford $11 \cdot 0$, and in Nottingham $13 \cdot 7$-all industrial counties.

Hereford, Feb. 13th, 1906.

$$
\text { I am, Sirs, yours faithfully, }
$$
HERBERT JONES,

\section{TREATMENT OF APPENDICITIS AND ALLIED BOWEL TROUBLES BY HIGH-UP INJECTION}

To the Editors of THE LANCET.

Sirs,-At a meeting of the Medical Association held in Toronto on June 6th, 1895, I read a paper showing that the ordinary indiarubber syringe presents several faults of construction. Its vaginal attachment is of such small size that it does not smooth out the mucous folds and therefore the wash-water or medicine does not reach the irritated or ulcerated surfaces; the ear-nozzle ought also to be of soft indiarubber as less likely to injure delicate structures. My principal object, however, on the present occasion is to point out that the hard short nozzle used for the administration of enemata per rectum is in several respects objectionable. Being short it does not reach far enough to deliver its charge where it would do most good, and, being hard, it impinges on the sphincter muscle and thus stimulates to expulsive action; the injection being delivered low down is speedily voided; and little opportunity therefore is given for solvent action on the contents of the bowel. I then proposed the using of an elastic indiarubber tube from 50 to 60 inches long and similar in calibre and character to the tube used in washing out the stomach. With such an apparatus, solvents, antiseptics, or purgatives could he introduced at a point to serve the purposes intended. At this time I gave it as my experience that the soft indiarubber tube is not only a valuable agent in the relief of obstinate constipation, impaction of fæces, invagination, and muco-enteritis, but it is also of pre-eminent utility in the treatment of appendicitis.

Since writing that paper more than ten years ago I have had abundant opportunity of further observation and although I have had some very serious cases under treatment $I$ have yet to meet one in which surgical interference was necessary nor have I one death to record. The emptying of the bowel and the remuval of irritating matter are not the only effects of high-up injection, for when the bowel is distended the appendix is retracted and distended, and in this way the fluid injected has a chance to enter and remove sources of irritation when immediately within the appendix, and in this way is more largely curative. I do not hold that this or any other medical or expectant treatment will in all cases super. sede the knife ; for instance, when the patient's temperature has increased with subsequenti sudden lowering and the formation of pus is suspected I certainly would not rely on medical treatment alone. It is, however, well to remember (1) that Dr. O. Hanolan has stated from personal observation that in 42 necropsies in which a previous diagnosis of appendicitis had been made 32 of the deceased were found to have normal appendices; and (2) that Dr. Horrick has related that in the French army 188 cases were operated upon with 23 deaths, and 480 were treated medicinally with five deatbs. Surgeons of experience maintain that it is best to operate early, but in my opinion there is little danger in delay if the patient is given easily digested non.fermentable food, rest in bed, antiphlogistine (a combination of clay, glycerine, boric acid, menthol, and eucalyptus) over the bowels or a cold compress. The measures which I take to mark the ne plus ultra in the treatment of appendicitis are as follows: the filling (or rather the complete dilating) of the bowel by means of the long tube with sweet oil, glycerine, and water, or soap and water; hypodermic injections of morphine or morphine and atropine ; and complete abstinence from food or the taking of it sparingly in order to secure digestive rest. The following case supplies a good example of the extent to which by the long tube an injection may be forced. The patient, who was a man about 40 years of age, weighing about 275 pounds and of immense girth, had partaken heartily of pork and beans. He was normally a large eater, consuming 4 or 5 pounds of steak, with potatoes, toast, and so forth, at a sitting. When I saw him he was suffering from severe pain in the bowels, which were constipated and much distended with gas and food. The medical men who treated him in a village some distance from Lindsay had used the low-down injection repeatedly and had given him purgatives without effect. I at once used a tube fully six feet long and after one or two very scanty evacuations succeeded in passing the tube for its entire length and pumped in a gallon or two of warm water, the abdomen being kneaded at the same time. There was considerable vomiting, after which the injection entered more readily. When a large quantity of fluid had been used the patient began to cry out that he would certainly burst. The vomiting became more continuous and smelt of peppermint which had been added to the injection as an anti-flatulent. The vomiting with the continued pressure of the injection had evidently reversed the peristaltic action and there was no doubt that the water flavoured with peppermint had passed completely through the alimentary tract and was being ejected by the stomach through the mouth. The distension and soreness were relieved and the patient made a quick recovery. Another case which was almost a complete replica of the foregoing one was published by Dr. E. E. Tope in the Medical World of August, 1904 . He does not give the length of the tube employed but writes: "A large rectal tube was passed the full length into the bowel. ...... We kept on pumping water into the patient and calling for more water while the patient kept vomiting it up until we had used more than five gallons and the water was no longer discoloured." I need not enter into a controversy as to the possibility of passing the ileo-cæcal valve, for in these cases there is no doubt that the long tube placed the injection beyond that poirt and so far up that peristalsis was reversed and the stomach accepted the inevitable. This is, perhaps not after all so very strange, as in incarcerated bowel and even in appendicitis stercoraceous vomiting occurs and a soon as it is admitted that the ileo-cæcal valve may be passed the rest would appear easy.

I am, Sirs, yours faithfully,

$$
\text { P. Palmer Burrows, M.D., C.M. }
$$

President of the Association of Health Officers, Member of the American Public Health Association, and Member of the Dominion Medical Association.

Lindsay, Ontario, Canada, Jan. 20th, 1906.

\section{THE COST OF ANTITOXIN.}

\section{To the Editors of THE LANCET.}

SIRs.-The reading of the most excellent article on Some Points in the Treatment of Heart Failure in Diphtheria by Dr. Charles Bolton has led me to make an appeal to the makers of diphtheria antitoxin as to whether the time has not arrived when this valuable remedy for the treatment of so fatal a disease cannot be retailed to the profession at a 